\title{
Metodologia Ativa na Educação a Distância: competências do tutor
}

\author{
Gisela de Amorim Costa, \\ Isabela Cristini Gonçalves de Oliveira, \\ Márcia Cristine Althoff, \\ Vanessa do Amaral, \\ Giovanni Ferreira de Farias
}

\section{INTRODUÇÃO}

Discursar sobre conhecimentos, habilidades e atitudes de um tutor no acompanhamento de cursos a distância remete necessariamente às concepções inovadoras nos processos de ensino e aprendizagem em ambientes virtuais. Isso ocorre principalmente devido ao modo como as mudanças vem afetando hoje uma sociedade baseada no conhecimento.

Tais mudanças ampliam o espaço de reflexão tanto do docente quanto do discente, de forma a mudar a dinâmica comum em salas de aula, disponibilizar um problema e permitir que o estudante possa, de forma autônoma, criativa e com capacidade resolutiva, buscar alternativas para a questão, além da liberdade de propor outros pontos para serem discutidos.

O perfil do discente sofreu, de maneira destacada, mudanças com o acesso às tecnologias digitais. No entanto, continua em processo de transição, pois ainda muitos brasileiros não têm acesso a tais recursos. O estudante hoje na educação a distância $(\mathrm{EaD})$ ainda tem resquícios do modelo pedagógico presencial, apresentando, em alguns casos, dificuldades de lidar com a tecnologia, bem como de se empoderar de sua aprendizagem.

Diante da evidente demanda de $\mathrm{EaD}$, surge a questão norteadora deste artigo: que conhecimentos, habilidades e atitudes um tutor precisa ter para atuar no acompanhamento de cursos a distância que utilizam metodologias ativas? Para responder a esse questionamento, considera-se que a aprendizagem colaborativa parte do pressuposto de uma construção coletiva, resultado da interação, que também se dá pela experiência, pelo compartilhamento e troca de ideias.

Com isso, torna-se necessário abordar questões sobre as metodologias ativas no contexto do ensino na modalidade $\mathrm{EaD}$, sendo que o trabalho destaca a 
metodologia Problem Based Learning (PBL) como uma das principais estratégias de aprendizagem para promover maior colaboração e melhor interação entre os atores no processo.

\section{MÉTOdOS E CONCEPÇÕES}

Em uma pedagogia com concepção construtivista, o docente leva em conta o percurso do estudante e suas construções. Busca situações de aprendizagem visando à reflexão e a solução de problemas de forma ativa, e não mais passiva, por parte estudantes. O tutor nessa concepção também é um 'aprendiz', pois na relação com o discente, com o próprio conhecimento envolvido no processo e com as suas reflexões, atualizará todo o seu repertório de informações, de maneira também ativa, em interatividade com todos os atores envolvidos.

Krüger e Ensslin (2013) defendem que os métodos passivos de ensino colocam o professor como o centro de toda a atenção, onde ele assume o papel do sujeito ativo no processo de aprendizagem e o aluno o passivo. E por ser considerado o dono do conhecimento, nesse modelo, o professor é o grande responsável pelo ensino, apresentando aulas expositivas, teóricas, e repassando as informações sobre o conteúdo. Nesse contexto, o aluno está como espectador do que é dito, memorizando e repetindo o que se ouve e apenas assimilando o que lhe é dito sem muitos questionamentos (PINHO et al., 2010; KRÜGER; ENSSLIN, 2013).

A pedagogia na $\mathrm{EaD}$ deve deslocar a transmissão/depósito de informações para o diálogo e a construção de forma autônoma e colaborativa dos estudantes. Não se pode mais aceitar a visão comportamentalista de educação, onde os estudantes fiquem de forma passiva à espera das informações.

Nessa discussão sobre a importância do elo firmado entre a tutoria e o discente, pretende-se obter um aprendizado construído coletivamente, com base no diálogo e nos valores de colaboração e afetividade na mediação.

$\mathrm{Na}$ interação, três elementos são fundamentais na EaD: estudante, material didático e professor. O tutor é peça chave no desenvolvimento da modalidade $\mathrm{EaD}$, pois esse profissional tem a função de proporcionar situações de aprendizagem para desenvolver e favorecer o crescimento dos discentes.

Diante desse fato, o perfil do tutor deve conter competências como o conhecimento de diversos ritmos individuais dos discentes, deverá também apresentar inovações na elaboração do material didático, além de dominar os instrumentos de avaliação. O tutor deverá saber os fundamentos do processo didático, como proceder acerca do sistema de $\mathrm{EaD}$, além de conhecer as formas andragógicas do aprender. 
Para Paulo Freire (1997), o educador deve buscar o desenvolvimento de atitudes, e nessa busca entende que aprender é um processo constante de conhecimentos, que requer não apenas receber informações, mas transformá-las, de forma a dar-lhes sentido. Ainda para o autor, a educação deve ser autônoma, promover o diálogo, a problematização e ser difundida como instrumento de conscientização e libertação.

Da mesma forma, o ensino é um processo vinculado com a aprendizagem. E ensinar deve ser essa busca de formas, maneiras de informações significativas e de conhecimento, não devendo ser indissociável do aprender.

Não há ensino sem pesquisa e pesquisa sem ensino. Esses que-fazeres se encontram um no corpo do outro. Enquanto ensino continuo buscando, reprocurando. Ensino porque busco, porque indaguei, porque indago e me indago. Pesquiso para constatar, constatando, intervenho, intervindo educo e me educo. Pesquiso para conhecer o que ainda não conheço e comunicar ou anunciar a novidade [...]. (FREIRE, 1997, p. 32).

Seguindo esse raciocínio, Paulo Freire e a educação a distância, ambos, buscam formar indivíduos através do diálogo, da autonomia, da interatividade, além da participação e da consciência crítica.

Para Ausubel, Novak e Hanesian (1980), o fator isolado mais importante que influencia a aprendizagem é o que o aprendiz já sabe, assim, deve-se averiguar e ensiná-lo de acordo. Deve-se levar em conta a história do sujeito e ressaltar o papel dos docentes em propostas de situações que favoreçam a aprendizagem, pois há duas condições para que a aprendizagem aconteça: o conteúdo a ser ensinado deve ser potencialmente revelador; e o sujeito precisa estar disposto a relacionar o material de maneira consistente e não arbitrária. Dessa forma, o conhecimento prévio determina a quantidade de novas informações que podem ser processadas, sendo que esse conhecimento servirá de ancoragem para as novas informações, integrando-as em um processo elaborado que resultará na aprendizagem significativa.

Já na visão de Vygotsky (1998), o professor proporciona a construção de interações entre as Zonas de Desenvolvimento Proximal (ZDP), sabendo que a zona de desenvolvimento real é aquela que o indivíduo já construiu, e que se constitui através da solução independente de problemas; já o nível de desenvolvimento potencial é determinado por meio de solução de problemas em colaboração com o outro.

O tutor tem a função de orientar os discentes, de forma a oferecer o devido apoio e possibilidades, atividades, problematizar, possibilitando a Zona de Des- 
envolvimento Proximal de cada estudante, que é essa distância entre o desenvolvimento real e o potencial, de maneira que quanto maior a Zona de Desenvolvimento Proximal, maior será seu progresso quando utilizar a colaboração do outro.

\subsection{METODOLOGIAS ATIVAS DE ENSINO}

A sociedade em que vivemos demanda mudanças tanto nos indivíduos, quanto na sua forma de trabalhar, de se relacionar, de usufruir dos recursos naturais e, inclusive, na sua forma de aprender. Os métodos tradicionais, nos quais o estudante é visto como um ser passivo, que apenas absorve os conhecimentos transmitidos, e em que o professor é visto como o detentor exclusivo do saber, já ocupam espaços de menor destaque na educação.

A principal vantagem dos métodos tradicionalmente conhecidos é que o professor possui um maior controle da sala de aula, mas dentre as desvantagens observadas está a inexistência do desenvolvimento de um pensamento crítico por parte do discente, pois seu conhecimento fica limitado a informações que lhe foram repassadas.

$\mathrm{Na}$ tentativa de fazer com que os alunos sejam estimulados a pesquisar mais conteúdos, além dos aprendidos, muitos educadores têm complementado os métodos tradicionais com os chamados métodos ativos. São novos métodos pedagógicos, técnicas de ensino e ferramentas que, principalmente, fazem uso das tecnologias digitais e potencializam as chances de o aluno compreender o assunto, tornando-se um ser ativo no seu processo de ensino-aprendizagem. $\mathrm{O}$ docente passa a ser um facilitador, pois o discente passa a ser capaz de construir seu conhecimento (KRÜGER; ENSSLIN, 2013).

Nesse sentido, é um grande desafio estimular o estudante a ser um explorador de conteúdos e a não depender apenas do conhecimento do docente. Assim, as metodologias ativas de ensino surgem como uma proposta de contribuir para despertar a curiosidade do aluno, na medida em que elas trazem novos elementos na prática ainda não considerados nas aulas ou na própria perspectiva do docente (OLIVEIRA et al., 2012).

Fica claro que o uso de uma metodologia ativa exige uma readequação de hábitos, o que requer motivação, tempo e vontade dos atores envolvidos nesse processo educativo, pois é necessário mudar a postura passiva do estudante, que por tantos anos ficou cristalizado nas metodologias tradicionais. Nessa nova metodologia, o docente deixa de ser o centro do processo de ensino-aprendizagem para realizar o papel de facilitador (GOMES; REGO, 2011).

Em sala de aula, as metodologias ativas motivam os estudantes a serem 
agentes mais presentes e envolvidos no processo do aprender a aprender, aprender a fazer, aprender a ensinar e aprender a ser. De acordo com Simão Neto (2010), esses processos são fruto da interação entre os participantes, sendo potencializados pelos recursos tecnológicos, cada dia mais abundantes no contexto em que vivemos.

De acordo com Berbel (2011), para que as metodologias ativas possam causar efeito na direção da intencionalidade pela qual são definidas ou eleitas, será necessário que os participantes do processo possam compreendê-las no sentido de conhecer a melhor atuação na prática em sala de aula através dessas metodologias. E que o processo possa contribuir de forma efetiva para uma melhor formação crítica do estudante, atendendo às necessidades sócio-educacionais atuais.

Existem várias possibilidades de metodologias ativas que podem contribuir para que o discente aprenda de forma autônoma e crítica. Desse modo, para facilitar a descrição teórica e conduzir o restante da fundamentação, optou-se, neste artigo, por aprofundar uma das metodologias ativas, a Problem Based Learning (PBL), ou Aprendizagem Baseada em Problemas.

\subsection{PROBLEM-BASED LEARNING}

O PBL originou-se no ao final da década de 1960, no curso de Medicina da Universidade de McMaster, Canadá. Nessa abordagem são feitas discussões em pequenos grupos para a resolução do problema, ocorrendo assim o desenvolvimento de habilidades sociais, de aprendizagens significativas, além de a avaliação ocorrer também aos pares. Para Berbel (1998), o PBL tem docentes que orientarão as etapas de resolução do problema, organizando grupos e tendo como função despertar a busca de conhecimentos.

Segundo Freitas (2012), o PBL tem como objetivo o desenvolvimento de rotinas de estudo e de pensamento pelo método da experiência reflexiva, para melhorar o desempenho escolar dos estudantes e promover a autonomia na aprendizagem e a competência de trabalho em equipe, como se espera que ocorra na vida profissional.

Nesse sentido, o PBL rompe com a educação de cunho comportamentalista, tão criticada por Paulo Freire, e propõe que os estudantes sejam o centro da aprendizagem, sendo os tutores os incentivadores para essa postura autônoma e resolutiva. Para Howard Barrows (1996) e Ribeiro (2008), os princípios gerais da PBL podem ser:

a) Ensino centrado no aluno e visando ao seu processo de aprender; 
b) Responsabilização do aluno por sua aprendizagem;

c) Consideração de aprendizagens anteriores;

d) Aprendizagem ativa, interativa, e colaborativa;

e) Contextualização do ensino;

f) O papel principal do professor (instrutor, tutor) é criar situações-problema e coordenar sua solução;

g) O problema ou situação-problema sempre antecede a teoria;

h) Avaliação por pares.

Como na pedagogia libertária de Paulo Freire, o PBL estimula a aquisição ativa de conhecimento, onde o discente não é um elemento passivo, mas um ator atuante no processo educativo, empoderado em seu processo de aprendizagem. E como na Pedagogia Construtivista e Interacionista, os estudantes, discutem um problema específico, em que o tutor pode auxiliar na busca de fontes de informação para subsidiar a solução da situação problema, em um espaço de interatividade e compartilhamento de conhecimento.

Partindo dessa nova forma de ensinar e aprender, acredita-se que o "velho" jeito de ser docente já não se deve mais aplicar. São necessárias várias adaptações para que o docente esteja confortável para atuar com PBL, ou outra das metodologias ativas. Essas adaptações implicam a necessidade de capacitação do docente, para que possa atuar de forma condizente com as competências necessárias para agir nesse contexto educacional.

\subsection{COMPETÊNCIAS DA TUTORIA}

Litwin (2001) afirma que um bom docente deve propiciar ambiente para a reflexão, sugerir fontes de informação alternativa, oferecer explicações, bem como facilitar o processo de compreensão; para que seu objetivo de ensinar seja efetivo, deve guiar, orientar e apoiar o estudante. O tutor deve incentivar a autonomia de seus alunos, para que estes venham a formular seu próprio conhecimento.

Para Prado e Valente (2002), o profissional que trabalha com tutoria tem de ser capaz de refletir durante a ação pedagógica que realiza, e essa reflexão poderá reconstruir sua concepção do que é ensinar, modificando sua prática.

De acordo com os Referenciais de Qualidade para Educação Superior a Distância (BRASIL, 2007), o tutor tem de agir esclarecendo dúvidas por meio das ferramentas de comunicação, deve também promover espaços de construção coletiva de conhecimento, selecionar material didático básico, complementando-o, e participar dos processos avaliativos. 
Assim, sua postura é imprescindível para o bom andamento de todo o processo educacional, devendo ser preparado e capacitado. É preciso desenvolver, portanto, conhecimentos, habilidades e atitudes específicas para exercer o seu papel, com função estratégica na educação a distância.

Segundo Machado e Moraes (2015), algumas características da tutoria ativa são:

Estimular o estudo individual, com envio de mensagens individualizadas e personalizadas.

Dirimir dúvidas sobre o conteúdo e as atividades da disciplina.

Conduzir as tarefas individuais, em equipe, os fóruns de discussão, as reuniões online e os fóruns interdisciplinares.

Corrigir as tarefas individuais, as tarefas em equipe e as provas finais.

Orientar a realização de atividades individuais e coletivas.

Identificar quais são as dificuldades dos alunos e atuar prontamente.

Mediar atividades relacionadas.

Avaliar os fóruns e as reuniões online e reconhecer cada aluno.

Avaliar individualmente os trabalhos realizados na disciplina.

Distribuir atividades direcionadas para diminuir as dificuldades dos alunos.

Elaborar materiais para apoiar os alunos no processo de aprendizagem.

Realizar coaching com os alunos.

Já segundo a Resolução no 26 (BRASIL, 2009), as atribuições do tutor perpassam por mediar a comunicação de conteúdos, acompanhar as atividades discentes, apoiar o professor, manter a regularidade de acesso e dar retorno, estabelecer contato e mediar as atividades discentes, colaborar nas avaliações, participar das atividades de capacitação, elaborar relatórios e apoiar atividades presenciais.

Lima e Rosatelli (2005) relatam que existem algumas qualidades fundamentais que necessitam ser salientadas no tutor, tais como:

Apresentar atitude crítica, pesquisadora e criativa.

Estimular a resolução de problemas.

Proporcionar uma aprendizagem dinâmica.

Facilitar a expressão e a comunicação.

Fundamentar-se na produção e facilitar a construção de conhecimentos.

Possuir uma clara concepção de aprendizagem e capacidade de inovação. 
Estabelecer relações empáticas com os discentes.

O trabalho de tutoria é descrito por Sartori (2002, p. 30) como "o conjunto de ações educativas que apoia e orienta os alunos não só no caráter acadêmico, mas, também pessoal". Nesse contexto, o mesmo autor completa afirmando que o objetivo principal da tutoria é ajudar o aluno no desenvolvimento da sua interação social e, sobretudo, da sua independência na aprendizagem durante a apropriação do conhecimento sistematicamente organizado.

Tanto na literatura quanto na prática, observa-se que em todo processo de ensino e aprendizagem existem momentos de comunicação/interação entre estudante, material didático e professor. E em ambientes virtuais de ensino e aprendizagem (AVEA), as ferramentas (bilaterais) que propiciam interação "foram possíveis a partir do desenvolvimento e massificação da internet e são elas que conferem aos AVEA a capacidade de promover discurso interpessoal e construção social do conhecimento." (RISSI, 2013, p. 60).

Dentro da categoria das ferramentas bilaterais, Rissi (2013) destaca que as principais ferramentas de interação internas dos AVEA são: Chat, Wiki, e-mail, Mural e Fórum, sendo que ainda existem as ferramentas que necessitam de um link para serem incorporadas ao contexto dos cursos, como a videoconferência, que permite uma interação multidirecional, e a teleconferência, que é uma transmissão síncrona, porém, unidirecional.

O discente é considerado o centro da ação pedagógica na educação a distância e como tal precisa ter todos os subsídios para se tornar o protagonista do processo de ensino-aprendizagem. E é para apoiar esse processo educativo que a educação a distância conta com professores e tutores para inserir esse estudante no mundo tecnológico, orientá-lo e motivá-lo no decorrer do processo.

Os tutores são, portanto, sujeitos com grande responsabilidade na educação a distância, pois atuam de modo duplo, na comunicação entre professor e estudante, e de estudante com outros estudantes, devendo possuir o domínio das tecnologias disponíveis e usá-las da melhor forma, a fim de promover a interação.

Há uma nova maneira de ensinar e aprender. O tutor contribui muito para o processo de aprendizagem do aluno, com a responsabilidade de desenvolver um perfil "crítico, criativo e comunicativo" no discente. O bom funcionamento do método PBL está diretamente relacionado com o preparo e adaptação dos tutores. 


\section{METODOLOGIA}

O presente artigo foi desenvolvido a partir da perspectiva da pesquisa qualitativa de caráter exploratório, cujo delineamento é o levantamento bibliográfico.

Ozella (2003, p. 122) ressalta que "[...] a abordagem qualitativa pretende conhecer, esclarecer, entender e interpretar os processos que constituem os fenômenos, objetos de investigação". Nesse sentido, Richardson (1999) afirma que na pesquisa qualitativa do tipo exploratório busca-se conhecer, de forma mais completa, as características de um fenômeno. Ou seja, a abordagem qualitativa permite conhecer e interpretar, de forma mais ampla, o fenômeno que é objeto do estudo.

Matias-Pereira (2012) esclarece ainda que as pesquisas exploratórias são elaboradas visando à obtenção de uma visão geral acerca de determinado fenômeno que se pretende descobrir, desenvolver ou transformar, ideias e conceitos para a formulação de hipóteses pesquisáveis ou problemas mais precisos para estudos posteriores, onde o método de investigação torna-se explícito.

\section{ANÁLISE E RESULTADOS}

No processo educacional percebe-se que cada curso possui características distintas, tanto no que se refere ao conteúdo, à infraestrutura tecnológica, quanto ao público, equipe docente, equipe de tutoria, enfim, todos os atores envolvidos no processo. Apesar de não existir uma modus operandi padrão, existem cases de sucesso que devem ser considerados.

Fernandes et al. (2017) sugerem o uso de novas tecnologias digitais de âmbito educacional com a intenção de indicar aplicações que possam ser utilizadas por profissionais tutores interessados na inserção de tecnologias no ensino. As soluções sugeridas pelos autores foram fruto de pesquisas realizadas por eles, no ano de 2013, com base no Guia de Tecnologias do Ministério da Educação, o qual contém tecnologias que já estão sendo aplicadas com êxito no Brasil e no mundo e que facilmente podem ser adotadas e adaptadas para a realidade da prática.

Essas soluções, associadas à atuação de profissionais tutores preparados para o desenvolvimento das metodologias ativas como o PBL, estão dentro de um cenário ideal para uma provável solução dos grandes desafios relacionados aos alunos e profissionais educadores.

Para tanto, o desafio maior se dá na formação de tutores. Também é preciso aliar a qualidade à quantidade de educandos, para que o profissional possa des- 
envolver um efetivo trabalho, com resposta de forma imediata, demonstrando competência em seu papel de mediar o conhecimento.

Hoje, o investimento em formação continuada é um grande diferencial e vigora em todas as profissões. No entanto, essa ideia é especialmente aplicada para profissionais da educação. No que tange às competências para o trabalho de tutoria, listadas anteriormente, para exercer todas essas funções, um tutor necessita de formação especializada, de conhecimento, de habilidade e atitude para atuar significativamente no processo de aprendizagem.

Litwin (2001, p. 103) observa que "o tutor se encontra diante de uma tarefa desafiadora e complexa". O que nos remete aos alicerces do construtivismo pedagógico de Grossi e Bordin (1992), que corroboram o pensamento afirmando que o bom desempenho de profissionais da educação se baseia no conceito de que "só ensina quem aprende".

Ao nos depararmos com a realidade apresentada no presente artigo, observamos uma grande defasagem na quantidade de cursos oferecidos para a formação de tutores no Brasil.

Nesse aspecto, como curiosidade, realizou-se uma pesquisa exploratória a fim de observarmos os cursos que formam os tutores. Nessa pesquisa, ainda em andamento, percebe-se a grande demanda do mercado por esses profissionais e a grande deficiência na oferta de cursos de capacitação profissional nessa área.

A EaD é uma modalidade de ensino-aprendizagem que está em constante mutação e crescimento e que tem na qualificação de profissionais tutores uma suma importância para a formação e aquisição de competência para exercer sua função nesse mercado.

\section{CONSIDERAÇÕES FINAIS}

Ensinar e aprender não são processos dissociáveis. A EaD necessita de profissionais competentes com conhecimento, habilidade e atitude diante de uma metodologia ativa e tutoria ativa.

Diante do PBL, são necessários tutores que estabeleçam uma relação direta com os discentes, a tutoria ativa, que requer formação e atitude do profissional. A importância de conhecer tanto a tecnologia quanto o conteúdo específico que será abordado, e ter habilidade de comunicação, pois nessa metodologia o tutor é um grande mediador, instiga a aquisição de novos conhecimentos para entender a tecnologia e trabalhar de forma a desenvolvê-la com atitude.

O mercado de trabalho está cada vez mais competitivo e o diferencial dos profissionais está na competência. Na pesquisa exploratória realizada, perce- 
beu-se a grande deficiência na oferta de capacitação profissional em cursos de tutoria no país. Os poucos encontrados são superficiais em conteúdo e as metodologias ativas não são abordadas. Muitos são os cursos específicos para a formação de tutores que já estão atuando dentro de um curso $\mathrm{EaD}$; os cursos são ofertados em sua maioria como formação continuada e com diretrizes para o entendimento da metodologia da instituição da qual o tutor faz parte.

A excelência, que deve ser premissa da tutoria ativa, necessita de ferramentas de interação adequadas nos ambientes de ensino e aprendizagem. A possibilidade de incentivos na formação desses profissionais precisa ser pensada e apoiada por órgãos voltados a essa classe.

A tutoria está diretamente ligada ao fracasso ou ao sucesso da educação a distância, que, embora tenha distância em seu conceito, não deve ser distante do aluno, devendo ser cada vez mais presente no processo educacional e ativa no desenvolvimento da construção do conhecimento.

\section{REFERÊNCIAS}

AUSUBEL, D.; NOVAK, J. D.; HANESIAN, H. Psicologia educacional. Rio de Janeiro: Editora Interamericana, 1980.

BARROWS, H. S. Problem-based learning in medicine and beyond: a brief overview. In: WILKERSON, L.; GILSELAERS, H. (Ed.). Bringing problem-based learning to higher education: theory and practice. San Franscisco, CA: Jossey-Bass Inc., 1996.

BERBEL, N. A. N. A problematização e a aprendizagem baseada em problemas: diferentes termos ou diferentes caminhos? Interface, Botucatu, v. 2, n. 2, p. 139-154, 1998. Disponível em: <http://www.scielo.br/pdf/icse/v2n2/08.pdf>. Acesso em: 18 jul. 2017.

. As metodologias ativas e a promoção da autonomia de estudantes. Semina: Ci. Soc. e Hum., Londrina, v. 32, n. 1, p. 25-40, jan./jun. 2011. Disponível em: <http:// www.proiac.uff.br/sites/default/files/documentos/berbel_2011.pdf.> Acesso em: 17 jun. 2017.

BRASIL. Ministério da Educação. Referenciais de qualidade para Educação superior a distância. Brasília, 2007. Disponível em: <http://portal.mec.gov.br/seed/arquivos/pdf/ legislacao/refead1.pdf>. Acesso em: 29 jun. 2017.

. Resolução no 26, de 5 de junho de 2009. Diário Oficial da União, Brasília, DF, 8 jun. 2009.

FERNANDES, F. S. et al. Desafios da inserção das tecnologias da informação e comunicação no sistema educacional de Santa Catarina. p. 47-68. In: TEIXEIRA, Clarissa S.; SOUZA, Márcio V. de (Org.). Educação fora da Caixa: tendências para a educação no século XXI: [recurso eletrônico]. Florianópolis: Perse, 2017. (Sistematizações, experiências e práticas sobre a inovação na educação. v. 3). Disponível em: <http:// 
eduforadacaixa.com.br/principal/wp-content/uploads/2017/06/book-eduforadacaixa-vol3-3.pdf>. Acesso em 15 jul. 2017.

FREIRE, P. Pedagogia da autonomia. São Paulo: Paz e Terra, 1997.

FREITAS, R. Ensino por problemas: uma abordagem para o desenvolvimento do aluno. Educação e Pesquisa, São Paulo, v. 38, n. 2, p. 403-418, abr./jun. 2012. Disponível em: <http://www.redalyc.org/articulo.oa?id=29823285009>. Acesso em: 18 jul. 2017.

GOMES, A. P.; REGO, S. Transformação da educação médica: é possível formar um novo médico a partir de mudanças no método de ensino-aprendizagem? Rev. Bras. Educ. Med., Rio de Janeiro, v. 35, n. 4, p. 557-566, dez. 2011. Disponível em: <http:// www.scielo.br/scielo.php?script=sci_arttext\&pid=S010055022011000400016\&lng= en\&nrm=iso\&gt>. Acesso em: 18 jul. 2017.

GROSSI, E. P.; BORDIN, J. (Org.). Paixão de aprender. Petrópolis: Vozes, 1992.

KRÜGER, L. M.; ENSSLIN, S. R. Método tradicional e método construtivista de ensino no processo de aprendizagem: uma investigação com os acadêmicos da disciplina Contabilidade III do curso de Ciências Contábeis da Universidade Federal de Santa Catarina. Organizações em contexto, São Bernardo do Campo, v. 9, n. 18, p. 219270, jul./dez., 2013. Disponível em: <https://www.metodista.br/revistas/revistasims/ index.php/OC/article/viewFile/4306/pdf_82. lang="en-us" lang="en-us" xml:lang="en-us"> Acesso em: 10 jul. 2017.

LIMA, D. R.; ROSATELLI, M. C. Um sistema de tutor inteligente para um ambiente virtual de ensino-aprendizagem. Módulo Tutoria. Programa de Formação Continuada em Mídias na Educação. Brasília: MEC/SEED, 2005.

LITWIN, E. (Org.). Educação a distância: temas para debate de uma nova agenda educativa. Porto Alegre: Artmed, 2001.

MACHADO, D. P.; MORAES, M. G. S. Educação a Distância: fundamentos, tecnologias, estrutura e processo de ensino e aprendizagem. São Paulo: Érica, 2015.

MATIAS-PEREIRA, J. Manual de metodologia da pesquisa científica. 3. ed. São Paulo: Atlas, 2012.

OLIVEIRA, A. P. et al. Evaluation of a strategic practice demonstration method applied to endodontic laboratory classes. Rev. Odonto Ciênc., Porto Alegre, v. 27, n. 2, p. 127-131, 2012. Disponível em: <http://www.scielo.br/scielo.php?script=sci_ arttext\&pid=S1980-65232012000200006\&lng=en\&nrm=iso. style="line-height:115\%;">. Acesso em: 10 jul. 2017.

OZELLA, S. Pesquisar ou construir conhecimento: o ensino da pesquisa na abordagem sócio-histórica. In: BOCK, A. M. B. (Org.). A perspectiva sócio-histórica na formação em psicologia. Petrópolis: Vozes, 2003.

PINHO, S. T.; ALVES, D. M.; GRECO, P. J.; SCHILD, J. F. G. Método situacional e sua influência no conhecimento tático processual de escolares. Motriz, Rev. de Educação Física, Rio Claro, v. 16, n. 3, p. 580-590, jul./set., 2010. Disponível em: <http://www. scielo.br/pdf/motriz/v16n3/a05v16n3.pdf>. Acesso em: 10 jul. 2017.

PRADO, M. E. B.; VALENTE, J. A. A Educação a distância possibilitando a formação 
do professor com base no ciclo da prática pedagógica. In: MORAES, M. C. (Org.) Educação a distância: fundamentos e práticas. Campinas: UNICAMP/NIED, 2002.

RIBEIRO, L. R. C. Aprendizagem baseada em problema (PBL): uma experiência no Ensino Superior. São Carlos: EduFSCar, 2008.

RICHARDSON, R. J. Pesquisa social: métodos e técnicas. 3. ed. São Paulo: Atlas, 1999.

RISSI, M. A confiança e as relações interpessoais assegurando o compartilhamento do conhecimento no ambiente virtual de aprendizagem. Tese (Programa de Pós-graduação em Engenharia e Gestão do Conhecimento) - Universidade Federal de Santa Catarina, Florianópolis, 2013.

SARTORI, A. S. Metodologia da educação a distância. Florianópolis: UDESC/CEAD, 2002.

SIMÃO NETO, A. Cenários e modalidades da EaD. Curitiba: Iesde Brasil S. A., 2010.

VYGOTSKY, L. S. A formação social da mente. 6. ed. São Paulo: Livraria Martins Fontes, 1998. 
